\title{
The effect of hand muscle vibration on the somatosensory evoked potential in man: an interaction between lemniscal and spino- cerebellar inputs?
}

\author{
G ABBRUZZESE, M ABBRUZZESE, E FAVALE, M IVALDI, M LEANDRI, \\ AND S RATTO
}

From the Department of Neurology, University of Genoa

SUMMARY The effect of hand muscle mechanical vibration on the somatosensory potential (SEP) evoked by median nerve stimulation, was investigated in 10 healthy subjects. A marked decrease in the amplitude of the $\mathrm{N}_{17}, \mathrm{~N}_{20}$ and $\mathbf{P}_{25}$ components of the cerebral SEP was observed, while the $S_{11}$ and $S_{13}$ components of the cervical response did not change. The amplitude reduction of the SEP components was larger when low frequency vibration was used. Recordings performed after cooling the hand further suggest that the reduction of the amplitude of the SEP components induced by vibration is likely to depend on activation of muscle receptors. These findings could reflect an interaction between lemniscal and spino-cerebellar inputs, possibly occurring at the thalamo-cortical level, a concept compatible with the hypothesis that muscle spindle afferents do contribute to kinaesthesia or position-sense.

Muscle spindle primary endings have been shown, both in animals ${ }^{1}$ and in man, ${ }^{2}$ to be the main intramuscular vibration-sensitive receptors, responding to mechanical vibration over a wide frequency range. It is well known that the afferent fibres from these receptors ascend along the spino-cerebellar tracts, as well as via the dorsal columns. Muscle vibration may induce movement illusions or position-sense distortions ${ }^{34}$ : it has been suggested, therefore, that muscle spindle afferents could contribute to kinaesthesia or position-sense or both, which are classically related only to the lemniscal system. ${ }^{5}$ The relevance of possible interactions of cutaneous, joint and muscle afferents in kinesthesis has been pointed out. ${ }^{6}$ So vibration may induce functional changes in the lemniscal system. Such a hypothesis prompted us to investigate the effects of mechanical vibration of hand muscles on the somatosensory evoked potential (SEP), which is regarded as reflecting the activity of the lemniscal pathway, ${ }^{78}$ both at cortical and subcortical levels. ${ }^{9}$

Address for reprint requests: Dr G Abbruzzese, Clinica Neurologica Via De Toni, 5, I 16132 Genova, Italy.

Accepted 11 December 1979

\section{Material and methods}

Responses evoked over the scalp and the neck by median nerve (or finger I) stimulation were recorded in 10 normal subjects, aged 24 to 38 years. Stimulating bipolar electrodes were placed over the left median nerve, just proximal to the wrist, or strapped around the left thumb. The stimulus intensity at the wrist was two to four times motor threshold, while at finger I the intensity of stimulation was set to four times the sensory threshold, but always below the pain threshold.

Cerebral responses were recorded from the exploring electrode placed over the left hand projection area $(\mathrm{P})$, with a reference electrode on the upper forehead in the midline $(F)$ (see fig 1 , left). Cervical responses were obtained from an active electrode placed between the second and the third cervical spines (C), and a reference electrode on the right ear lobe (E) (see fig 1, left). An analysis time of $50 \mathrm{~ms}$ was used and 128 or 256 responses usually were summated. Stimulation, recording and averaging techniques have been described elsewhere. ${ }^{10}$

The neurogram of the left median nerve was 


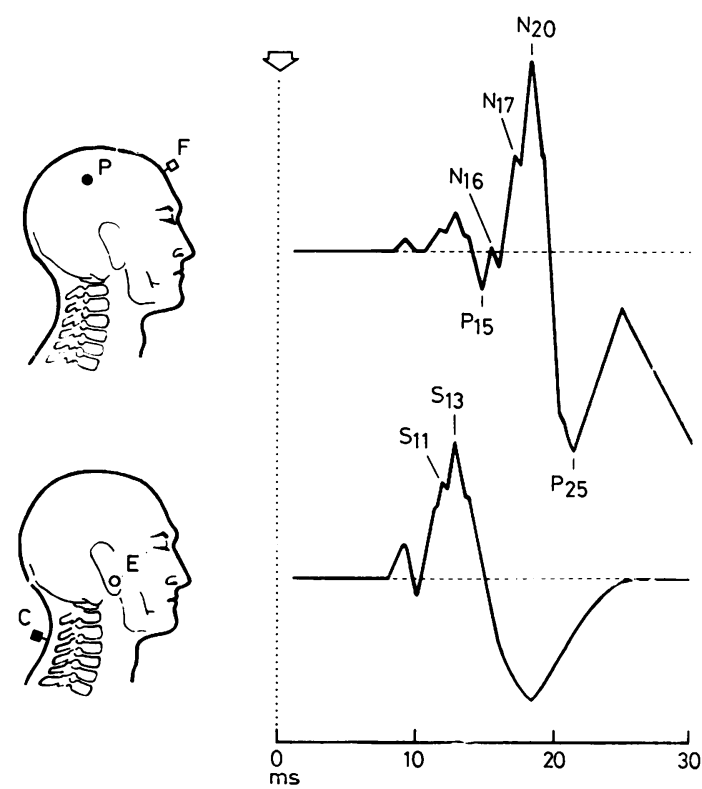

Fig 1 Left: Electrode placements for recordings of cerebral (upper) and cervical (lower) responses evoked by left median nerve stimulation. $P=$ left hand projection area; $F=$ upper forehead on the midline; $C=$ between second and third cervical spines; $E=$ right ear lobe.

Right: Schematic representation of the cerebral (upper) and cervical (lower) responses evoked by stimulation of the median nerve at the wrist. The components of both responses are indicated.

The peak amplitude was measured with reference to the base-line (dotted).

recorded at the Erb's point, by means of subcutaneous needles, according to Desmedt et al. ${ }^{11}$

A small cylindrical vibrator (Keydon VibratorUppsala), secured over the left hand thenar eminence by rubber bands, was used to vibrate the hand muscles. Vibration amplitude was $0.5-$ $1.0 \mathrm{~mm}$ and two different frequencies $(60 \mathrm{~Hz}$ and $120 \mathrm{~Hz}$ ) were employed. In six subjects the contralateral hand muscles and the ipsilateral triceps surae muscle were vibrated as well.

Recordings were performed while the subjects were relaxed on a couch in a quiet room, with the supinated left hand resting on the couch seat. Separate recordings of evoked potentials were obtained before, during and after muscle vibration. Under each of these experimental conditions, both latency and amplitude of the following components were measured (see fig 1 , right): $\mathrm{N}_{17}$, $\mathbf{N}_{20}$ and $\mathbf{P}_{25}$ components of the cerebral evoked response $^{9}$ and $S_{11}$ and $S_{13}$ components (as well as the subsequent large positive deflection) of the cervical evoked response. ${ }^{12}$ Because of their small amplitude, neither $P_{15}$ nor $N_{16}$ components of the cerebral SEP $^{9}$ were measured.

In addition, control experiments were also performed after the left hand had been cooled by means of ice cubes placed over the skin under the vibrator for different periods of time (2 to 15 minutes), while both cutaneous and intramuscular temperatures were measured by an electronic thermometer (DISA 14 G 05).

Statistical evaluation of data was performed by Student's $t$-test for paired data.

\section{Results}

During vibration the subjects experienced illusions of a continuing movement, described as a slow hand pronation, associated with a decreased intensity of the sensation induced by the electrical shocks.

The mean latencies of the cerebral SEP components under investigation (that is $\mathrm{N}_{17}, \mathrm{~N}_{20}$ and $\mathrm{P}_{25}$ ) were not modified by hand muscle vibration. The same was true for both $S_{11}$ and $\mathrm{S}_{13}$ components of the response concurrently recorded over the upper neck. In either case only minor, statistically not significant, latency shifts could be observed.

In all the subjects the vibratory stimulation induced a marked decrease in the amplitude of $\mathrm{N}_{17}, \mathrm{~N}_{20}$ and $\mathrm{P}_{25}$ components of the cerebral SEP evoked either by median nerve stimulation at the wrist (fig $2 \mathrm{~A}$ ) or by cutaneous stimulation of finger I (fig 3A), table 1). In contrast, the mean

Table 1

\begin{tabular}{|c|c|c|}
\hline \multirow[t]{2}{*}{ Components } & \multicolumn{2}{|c|}{ Amplitude decrease $(\%)$ during vibration $(L F+H F)$} \\
\hline & $\overline{M e a n+S D}$ & $t$-test $(n=20)$ \\
\hline $\begin{array}{l}\mathbf{S}_{11} \\
\mathbf{S}_{13} \\
\mathbf{N}_{17} \\
\mathbf{N}_{20} \\
\mathbf{P}_{25}\end{array}$ & $\begin{array}{r}6 \cdot 4 \pm 23 \cdot 9 \\
11 \cdot 3 \pm 25 \cdot 9 \\
38 \cdot 9 \pm 22 \cdot 9 \\
41 \cdot 1 \pm 16 \cdot 2 \\
43 \cdot 0 \pm 25 \cdot 7\end{array}$ & $\begin{array}{l}\text { N.S } \\
\text { N.S. } \\
p<0.001 \\
p<0.001 \\
p<0.001\end{array}$ \\
\hline
\end{tabular}

*Recordings at low frequency (LF) and high frequency (HF) vibration were pooled together.

Table 2

\begin{tabular}{llll}
\hline \multirow{3}{*}{ Components } & \multicolumn{3}{l}{ Amplitude decrease $(\%)$ during vibration $(L F \text { vs } H F)^{*}$} \\
\cline { 2 - 4 } & $\begin{array}{l}\text { Low frequency } \\
\text { Mean } \pm S D\end{array}$ & $\begin{array}{l}\text { High frequency } \\
\text { Mean } \pm S D\end{array}$ & t-test $(n=10)$ \\
\hline$S_{11}$ & $8 \cdot 3 \pm 27 \cdot 4$ & $4 \cdot 4 \pm 21 \cdot 1$ & N.S. \\
$S_{13}$ & $5 \cdot 1 \pm 30 \cdot 3$ & $17 \cdot 5 \pm 20 \cdot 3$ & N.S. \\
$\mathrm{N}_{17}$ & $52 \cdot 4 \pm 17 \cdot 2$ & $25 \cdot 5 \pm 20 \cdot 1$ & $\mathrm{p}<0.001$ \\
$\mathrm{~N}_{20}$ & $51 \cdot 1 \pm 11 \cdot 7$ & $31 \cdot 1 \pm 14 \cdot 2$ & $\mathrm{p}<0.001$ \\
$\mathrm{P}_{25}$ & $53 \cdot 3 \pm 21 \cdot 7$ & $32 \cdot 7 \pm 26 \cdot 2$ & $\mathrm{p}<0.01$ \\
\hline
\end{tabular}

*Recordings at low frequency (LF) and high frequency (HF) vibration were compared. 

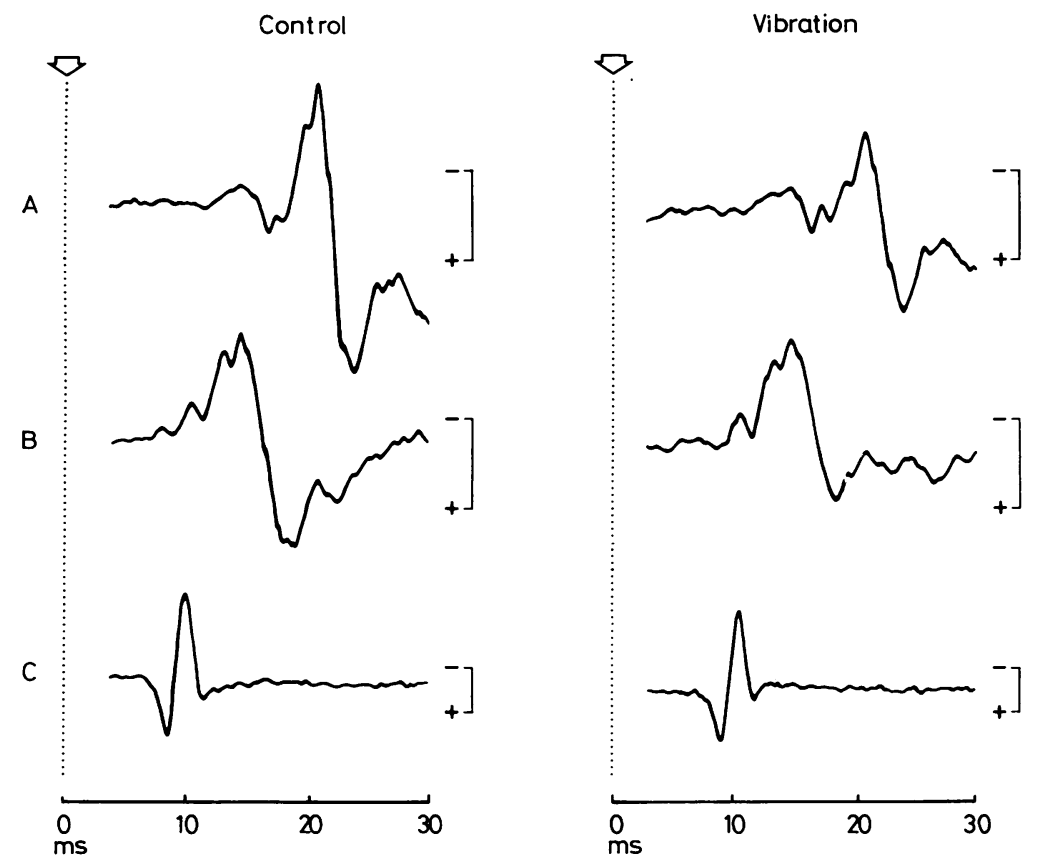

Fig 2 Concurrent recordings of: cerebral response $(A)$, cervical response $(B)$ and peripheral nerve potential at Erb's point $(C)$ evoked by stimulation of the left median nerve at the wrist, before (left) and during (right) vibration $(60 \mathrm{~Hz})$ of the left hand muscles. $N_{17}, N_{20}$ and $P_{25}$ components of the cerebral response showed a marked amplitude reduction during vibration, while $S_{11}$ and $S_{13}$ components of the cervical response did not show signifcant changes; the peak-to-peak amplitude of the median nerve potential was slightly reduced. Calibration: $1 \mu V$ in $A, B$ and $C .256$ responses were summated.

amplitude of the $S_{11}$ and $S_{13}$ components of the cervical response was slightly, but not significantly reduced (see figs $2 \mathrm{~B}, 3 \mathrm{~B}$ and table 1 ). It should be pointed out, however, that the cervical response may be contaminated by the muscle noise associated with the developing "tonic vibration reflex". The large positive deflection following $S_{13}$ was constantly reduced (figs $2 B$ and $3 B$ ).

The changes in amplitude of the cerebral SEP components were dependent on the vibration
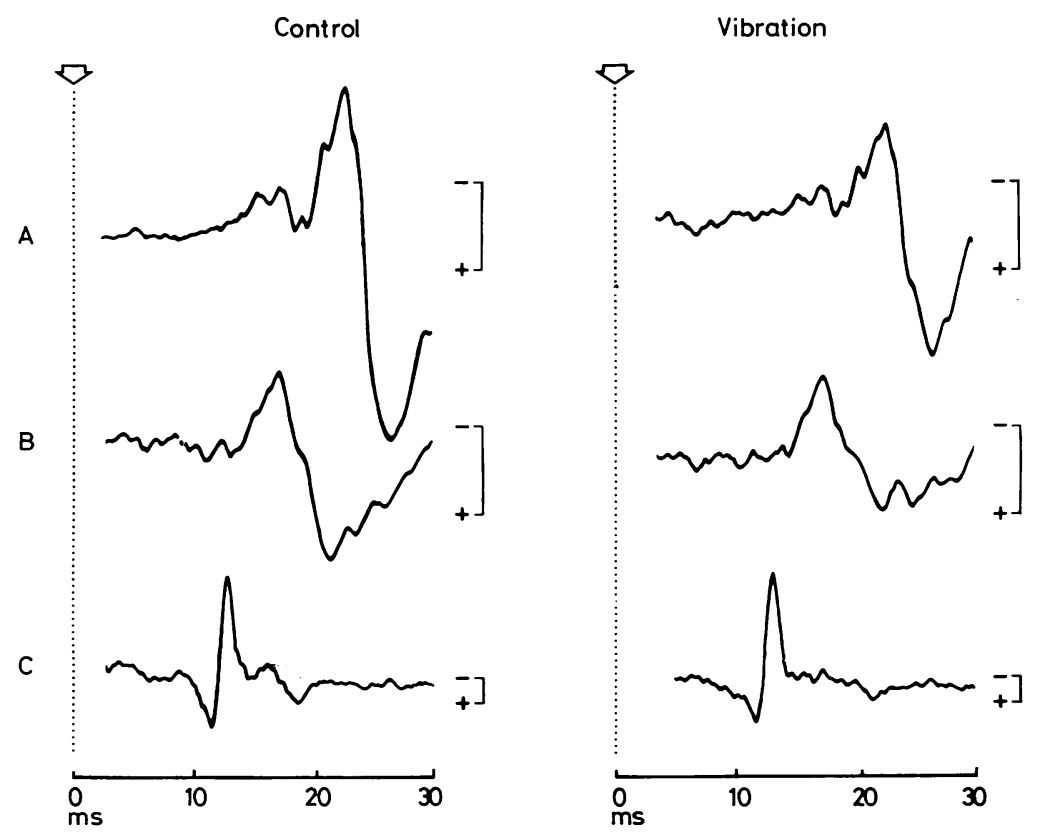

Fig 3 Concurrent recordings of: cerebral response $(A)$, cervical response $(B)$ and peripheral nerve potential at Erb's point $(C)$ evoked by stimulation of the left finger $I$, before (left) and during (right) vibration of the left hand muscles. $N_{17}, N_{20}$ and $P_{25}$ components of the cerebral response showed a marked reduction of amplitude during vibration, while $S_{11}$ and $S_{13}$ components of the cervical response did not show significant changes; the peak-to-peak amplitude of the median nerve potential was unchanged. Calibration: $0.3 \mu V$ in $A$ and $B, 0.5 \mu V$ in $C .256$ responses were summated. 
frequency, the decrease being always more pronounced at $60 \mathrm{~Hz}$ than at $120 \mathrm{~Hz}$ (see table 2). Neither $S_{11}$ nor $S_{13}$ were significantly affected by the vibration frequency (see table 2 ).

The median nerve neurogram during vibration varied with the site of stimulation. In particular, no change could be observed upon cutaneous stimulation of finger I (fig 3C), while a slight but significant $(p<0.01)$ reduction in amplitude occurred when the median nerve was stimulated at the wrist (fig 2C). In both cases, however, the mean latencies were not modified during vibration.

Vibration had no extended, long lasting effect on the cerebral SEP: both latency and amplitude of the SEP components, recorded immediately after the end of vibration, were unchanged as compared to the pre-vibratory controls.

No modification of the cervical and cerebral SEP was observed when vibrating the controlateral hand muscles or the ipsilateral triceps surae muscle.

The cerebral responses recorded during vibration were unaffected when cooling was performed for two to three minutes, to cause a $15^{\circ} \mathrm{C}$ (approximately) decrease of the cutaneous temperature, but no significant change in the intramuscular temperature. After a longer period of cooling (10 to 15 minutes), however, which lowered the intramuscular temperature by about $10^{\circ} \mathrm{C}$, the cerebral SEP components were larger than the responses recorded during vibration at the normal intramuscular temperature, at least in some subjects.

\section{Discussion}

We have shown that mechanical vibration of hand muscles reduces the amplitude of $\mathrm{N}_{17}, \mathrm{~N}_{20}$ and $\mathbf{P}_{25}$ components of the cerebral somatosensory response evoked by median nerve stimulation. It should be pointed out that $\mathrm{N}_{17}$ is supposed to reflect the activity of the thalamo-cortical radiation, ${ }^{9}$ while both $\mathrm{N}_{20}$ and $P_{25}$ represent the first cortical events of the SEP. ${ }^{8}$ It may be suggested, therefore, that mechanical vibration affects both the thalamo-cortical input and the primary cortical response evoked by stimulation of the median nerve.

On the other hand, neither $S_{11}$ nor $S_{13}$ components of the response concurrently recorded over the upper neck were changed. Any tendency to a reduction of the amplitude during vibration may not have reached statistical significance because of the unfavourable signal to noise ratio occurring in cervical recordings, as compared to both peripheral and cortical recordings. So, assuming that the $S_{11}$ and $S_{13}$ components are related to the activity of the cervical dorsal columns and of the dorsal columns nuclei respectively, ${ }^{12}{ }^{13}$ one cannot definitely be sure that the conduction in the lemniscal pathway is not modified by mechanical vibration either at spinal or at bulbar levels. As to the amplitude reduction of the large positive deflection following $S_{13}$, this deflection is due largely to a far field potential generated at both thalamic and cortical levels, ${ }^{14}{ }^{15}$ so changes in this wave are related to the behaviour of $\mathrm{N}_{17}$ and $\mathrm{N}_{20}$ SEP components.

Concurrent recordings of the median nerve neurogram, on stimulation at the wrist, showed a slight but statistically significant reduction in amplitude during vibration, not observed by Delwaide $^{16}$ in the sciatic nerve. Such a reduction could be due to a "busy line" occlusion of Ia afferents, owing to the engagement of the primary endings by vibratory stimulation, as suggested by Hagbarth. ${ }^{17}$ It must be noted, however, that during vibration the $\mathrm{N}_{17}, \mathrm{~N}_{20}$ and $\mathrm{P}_{25}$ components of the somatosensory response evoked by stimulation of finger I were modified in a way similar to that occurring on stimulation at the wrist, though the amplitude of the median nerve potential remained unchanged. It can be safely assumed, therefore, that vibration-induced peripheral "occlusion" per se does not affect the cerebral SEP components. Inhibitory mechanisms, acting at a more rostral level, should be, therefore, considered.

Mechanical vibration of a human limb is known to excite muscle as well as skin and joint receptors. The Pacinian corpuscles, however, are most sensitive to high frequency vibration, ${ }^{18}$ while the strongest effect in our experiments was obtained at low frequency vibration. Moreover, the results of cooling-tests showed that the effect of vibration on the cerebral SEP components was not modified at a temperature impairing skin but not muscle receptor sensitivity. In contrast, after prolonged cooling, which is likely also to affect muscle receptor sensitivity, ${ }^{19}$ the reduction of the cerebral SEP components was less pronounced than at the normal intramuscular temperature.

Our results seem consistent with the hypothesis that vibration activates muscle receptors. This activation may interfere with conduction in the lemniscal pathway, either directly (as the Ia afferents have been shown to project along the dorsal columns to the cerebral cortex ${ }^{20}{ }^{21}$ ) or through the spino-cerebellar system. The interaction might occur at the thalamo-cortical level, 
thus accounting for the reduction in the amplitude of $\mathrm{N}_{17}, \mathrm{~N}_{20}$ and $\mathrm{P}_{25}$ SEP components, but the possibility of an interaction at dorsal columns nuclear level cannot be ruled out.

The different effect of low versus high frequency vibration on the cerebral SEP components cannot be explained on the basis of the present findings. The more pronounced effect of the lower vibration frequency could depend, however, on the simultaneous activation of both primary and secondary endings. ${ }^{2}$ The possible relevance of this finding to the different perceptual effects at low and high frequency vibration described by McCloskey ${ }^{22}$ should be investigated.

In conclusion, our results suggest that an interaction between lemniscal and spino-cerebellar inputs may occur, possibly at the thalamocortical level, supporting the hypothesis that muscle spindle afferents do contribute to kinaesthesia and position-sense. ${ }^{623}$

We thank Prof. Karl-Erik Hagbarth (Department of Clinical Neurophysiology, University Hospital, Uppsala) for his helpful suggestions and criticisms.

\section{References}

1 Bianconi R, Van der Meulen JP. The responses to vibration of the end organs of mammalian muscle spindles. J Neurophysiol 1963; 26:177-90.

2 Burke D, Hagbarth K-E, Lofstedt L, Wallin BG. The responses of human muscle spindle endings to vibration of non-contracting muscles. J Physiol 1976; 261:673-93.

3 Eklund G. Position sense and state of contraction: the effects of vibration. J Neurol Neurosurg Psychiatry 1972; 35:606-11.

4 Goodwin GM, McCloskey DI, Matthews PBC. The contribution of muscle afferents to kinesthesia shown by vibration induced illusions of movement and by the effects of paralysing joint afferents. Brain 1972; 95:705-48.

5 Mountcastle VB. Medical physiology. 12th edition. St. Louis: Mosby, 1968.

6 McCloskey DI. Kinesthetic sensibility. Physiol Rev 1978; 58:763-820.

7 Halliday AM, Wakefield GS. Cerebral evoked potentials in patients with dissociated sensory loss. J Neurol Neurosurg Psychiatry 1963; 26: 2.11-9.

8 Desmedt JE. Somatosensory evoked potentials in man. In: Remond A, ed. Handbook of EEG and clinical neurophysiology. Amsterdam: Elsevier, 1971; vol 9: 55-82.

9 Abbruzzese $\mathbf{M}$, Favale $\mathrm{E}$, Leandri $\mathbf{M}$, Ratto $\mathbf{S}$. New subcortical components of the cerebral somatosensory evoked potential in man. Acta Neurol Scandinav 1978; 58:325-32.

10 Abbruzzese M, Favale E, Leandri M, Ratto $\mathbf{S}$. Spinal components of the cerebral somatosensory evoked response in normal man: the "S wave". Acta Neurol Scandinav 1978; 58:213-20.

11 Desmedt JE, Nöel $P$, Debècker $J$, Namecke $J$. Maturation of afferent conduction velocity as studied by sensory nerve potentials and by cerebral evoked potentials. In: Desmedt JE, ed. New developments in electromyography and clinical neurophysiology. Basel: Karger, 1973; vol 2: 52-63.

12 Abbruzzese M, Favale E, Ivaldi M, Leandri M, Ratto S. Nuove acquisizioni sulla risposta cervicale somestesica. Riv Ital Elettroencef Neurofisiol 1980; (in press).

13 Jones SJ. Short latency potentials recorded from the neck and the scalp following median nerve stimulation in man. Electroencephalogr Clin Neurophysiol 1977; 43:855-63.

14 Shimoji K, Shimizu H, Maruyama Y. Origin of the somatosensory responses recorded from the cervical skin surface. $J$ Neurosurg 1978; 48: 980-4.

15 Abbruzzese $\mathbf{M}$, Favale E, Leandri $\mathbf{M}$, Ratto $\mathbf{S}$. Ricerche sulle componenti encefaliche del potenziale spinale evocato da stimolazione del nervo mediano nell'uomo. Boll Soc Ital Biol Sper 1978; 54:1925-30.

16 Delwaide PJ. Etude expérimentale de l'hyperréflexie tendineuse en clinique neurologique. Bruxelles: Arscia, 1971.

17 Hagbarth K-E. The effect of muscle vibration in normal man and in patients with motor disorders. In: Desmedt JE, ed. New developments in electromyography and clinical neurophysiology. Bassel: Karger, 1973; vol 3: 428-43.

18 Talbot WH, Darian-Smith I, Kornhuber HH, Mountcastle VB. The sense of flutter-vibration: comparison of the human capacity with response patterns of mechanoreceptive afferents from the monkey hand. J Neurophysiol 1968; 31:301-34.

19 Eldred E, Lindsley DF, Buchwald JS. The effect of cooling on mammalian muscle spindles. Exp Neurol 1960; 2:144-57.

20 Rosen I. Excitation of group I activated thalamocortical relay neurones in the cat. J Physiol 1969; 205:237-55.

21 Phillips CG, Powell TPS, Wiesendanger $M$. Projection from low-threshold muscle afferents of hand and forearm to area 3a of baboon's cortex. J Physiol 1971; 217:419-46.

22 McCloskey DI. Differences between the sense of movement and position shown by the effects of loading and vibration of musces in man. Brain Res 1973; 63:119-31.

23 Matthews PBC. Muscle afferents and kinaesthesia. Brit Med Bull 1977; 33:137-42. 